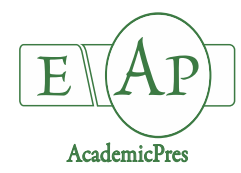

Horodnic SA and Roibu CC (2020)
Notulae Botanicae Horti Agrobotanici Cluj-Napoca 48(2):1085-1099
DOI: $10.15835 /$ nbha48211949
Research Article

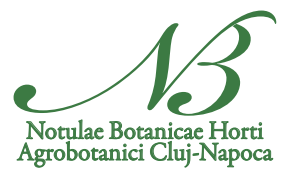

\title{
Collective growth patterns reveal the high growing potential of older silver fir trees in a primeval forest in Romania's Southern Carpathians
}

\author{
Sergiu A. HORODNIC*, Cătălin C. ROIBU \\ University "Ştefan cel Mare”of Suceava, Faculty of Forestry, 13 Universității, 720229, Suceava, Romania; horodnic@usv.ro \\ ( ${ }^{*}$ corresponding author); catalinroibu@gmail.com
}

\begin{abstract}
The trees' ability to respond and adjust to very different growing conditions during their lifespans varies depending on tree species and the site-specific situations. Identifying the underlying mechanisms and the individual drivers that may affect the patterns of tree growth is crucial in ecological and economic terms. How long can forest trees grow and sustain biomass accumulation, with increasing age, is still under debate. In order to determine the factors that influence growth releases for silver fir (Abies alba Mill.) trees in a temperate oldgrowth forest of Romania's Southern Carpathians, an analysis of radial and basal area growth patterns was initiated. Dendroecological methods were used to reconstruct radial growth both at the individual level, but especially at the group level, in four clusters obtained by a prior $\mathrm{k}$-cluster analysis depending on social status. The study results showed that the growth rate of older trees increases continuously for this species at stand level, even after the typical harvesting age in managed forests. Although the direction and intensity of the climate-growth correlations at individual level were very different, the considered climatic variables explaining little to none of the growth variation, the cumulative response of the analysed trees to climate change is directly correlated with the mean July-August temperature, confirming the capacity of the silver fir to tolerate drought. Our results demonstrate that the trees of the same species are able to obtain together a temporal plasticity in strategies, exceeding the adaptability of individuals considered separately and suggest the positive impact of facilitative intraspecific interactions on forest growth.
\end{abstract}

Keywords: basal area increment; collective growth patterns; ecological modelling; intraspecific facilitation; old-growth forest

\section{Introduction}

A long-standing premise in forest ecology is that the growth rate with increasing age of individual trees conforms to unimodal optimum curves: an initial period of increasing growth and a decline after reaching a peak in the early to early-mature stages (Pretzsch, 2009; Sillett et al., 2010; Stephenson et al., 2014). The studies of forest growth and yield (Assmann, 1970; Ryan et al., 1997) have first identified this pattern as common phenomenon for individual trees up to 50-150 years at least (Pretzsch, 2009) or for mono-specific stands (Sala et al., 2011), in even-aged forests up to 100-120 years, corresponding to ordinary rotation cycle in forestry practices in central Europe (Castagneri et al., 2013). Such age-related declines of tree and forest productivity 
have been attributed to changes in carbon use efficiency (respiration hypothesis) or to decreases nutrient supply and carbon sources (assimilation hypothesis) with potential causes including hydraulic limitation of plant height, reductions of leaf area from abrasion in the crowns, and genetic factors (Ryan et al., 1997; Sala et al., 2011; Michaletz et al., 2014).

Recent worldwide studies (Stephenson et al., 2014) contradict the commonly held assumption that tree growth eventually declines as trees get older. Thus, are confirmed the previous observations (Assmann, 1970; Sillett et al., 2010) made in multi-storey stands with wide age differences, mostly for individual trees over 300 years old, according to which wood production of the entire tree (or stand) makes irregular progress, but the growth of diameter (and, consequently, of the volume) may continue long after height growth has slowed down. These findings suggest that the growth rate of older trees continuously increases with increasing size (Stephenson et al., 2014; Trotsiuk et al., 2016).

However, it is difficult to separate, even in theory, the proposed drivers of growth from tree age and size effects (Carrer, 2011; Niukkanen and Kuuluvainen, 2011; Rohner et al., 2018) because they are closely intercorrelated with global and regional environmental change (climatic variability, $\mathrm{CO}_{2}$ increases or nitrogen deposition), site conditions (topography, soil properties, nutrient availability), and local competitive trends (inter-tree interaction, social status, and stand dynamics).

There are very few studies that deal with the importance of tree-to-tree interactions in modulating the growth response to climatic and structural factors in forests without human or severe natural disturbances (Rozas, 2015). To date, the competitive interactions for uptake above- and below-ground resources are often invoked to explain plant species coexistence (Ehlers et al., 2016). It is increasingly recognized that there is a transfer of information between plants living in social groups (Callaway and Mahall, 2007; Gagliano, 2015) and the niche differentiation, determined by different sizes, favours neighbour interactions through which individuals may compete relatively intense with non-kin but cooperate (reduce competitiveness) with kin (Biernaskie, 2011). Two forms of cooperation were highlighted (Barker et al., 2017): exchanges between individual partners and collaborative production of fitness benefits shared among group members.

Representing a unique study area for understanding natural forest dynamics and ecosystem processes (Petritan et al., 2015), the most suitable for studying these relationships in terms of neighbourhood effects are the temperate old-growth forests, composed of long-lived shade-tolerant trees, because of their structural complexity reflected in the high variability of growth patterns (Niukkanen and Kuuluvainen, 2011) caused mainly by frequent small-gap openings (Di Filippo et al., 2017). In order to investigate the range of age-related responses to relevant biophysical variables and for quantifying the effects of inter-tree interaction on their growth, old-growth forests are typical systems distinguished by the presence of long-lived mature trees that contain the majority of biomass and that influence all other stages of the life cycle (Kunstler et al., 2011). Looking into the past via dendroecological procedures, one can describe the disturbances over time in oldgrowth stands by identifying growth suppressions and releases (Assmann, 1970; Black and Abrams, 2004; Di Filippo et al., 2017).

The specific objective of this study was to determine the growth patterns at individual and collective level for silver fir trees, one of the dominant species in a particular old-growth forest, in order to assess whether their radial and basal area growing rate increase as they get older. We started from the hypothesis that such reactions and relationships can be better highlighted through a small-scale analysis, to ensure the homogeneity of site conditions, and in stands unaffected by human intervention. 


\section{Materials and Methods}

Study site

The study area was located in the natural silver fir (Abies alba Mill.) and beech (Fagus sylvatica L.) oldgrowth forest Şinca (http://www.padurilesincii.ro/tur_virtual/turvirtual.html), located in the Făgăraş Mountains (Southern Carpathians, Romania). This is a primeval forest included on the World Heritage List of UNESCO, and the criteria for choosing this location were the strong virgin character without any recent anthropogenic disturbance and the high number of trees with age over 250 years. The Şinca old-growth forest was shaped by randomly distributed small-scale disturbances (Petritan et al., 2015). The climate is temperate continental with a mean annual temperature of $4.5^{\circ} \mathrm{C}$ and a mean annual precipitation of $1000 \mathrm{~mm}$. The bedrock consists of crystalline schist and the main soils are cambisols characterized by ample water and nutrient supply (Petritan et al., 2015). The sampling area installed in 2013 for this study was a permanent rectangular plot of one hectare (centred at $45^{\circ} 39^{\prime} 88^{\prime \prime} \mathrm{N}$ and $25^{\circ} 10^{\prime} 14^{\prime \prime} \mathrm{E}$ ) within a total reserve area of $351.80 \mathrm{ha}$, at an elevation of $978 \mathrm{~m}$ a.s.l.

\section{Data collection}

In the sample area of 1 ha, all standing trees at least $6.0 \mathrm{~cm}$ diameter at breast height (DBH) were stemmapped and marked with numbered tags. In addition to stem position, dimensional characteristics (DBH, total tree height, width and height of the crown), species, social class (dominant, co-dominant, sub-dominant and suppressed), and vitality attributes (live/dead) were recorded for all standing stems (Bosela et al., 2018). For lying deadwood $\geq 3 \mathrm{~m}$ and thick-end diameter $\geq 15 \mathrm{~cm}$ (Petritan et al., 2015), length and position were recorded and mapped. The spatial information about the position and $\mathrm{DBH}$ size of measured trees was transposed in two-dimensional representation (Figures $1 \mathrm{~A}$ and $1 \mathrm{~B}$ ). All recorded trees were cored with a $5 \mathrm{~mm}$ diameter Pressler increment borer at a height of $1.30 \mathrm{~m}$. The radial cores were prepared, mounted, sanded and then the annual tree ring widths were determined to $0.001 \mathrm{~mm}$ precision with a LINTAB measuring device (Rinntech, Germany).

To analyse long-term growth patterns within the study area, with synchronized chronologies in simultaneous development of component trees, we considered adequate to align annual increments to the biological (cambial) age at sampling height instead of calendar year (Schuster and Oberhuber, 2013). The cambial age of a given tree ring is the age of the cambium in the year when this tree ring was built, which is equivalent to the number of annual increments from the pith to that selected ring. Therefore, the maximum cambial age is the age of a section of stem at a certain level (in this case, considered $1.30 \mathrm{~m}$ ), with a deviation from the age of the tree equal to the number of years in which it grows up to the coring height.

Motivated by the complexity of interspecific relationships, even higher in the case of old-growth forests, but also because the rings of beech are much more difficult to cross-date due to frequent ambiguities (Assmann, 1970), we have chosen to limit our investigation to the silver fir species which, moreover, is the stand component represented numerically better, with 245 trees out of a total of 396 recorded trees. Taking into account the first aim of our study and getting longer chronologies, all subsequent analyses after measurements were restricted to fir trees $\geq 150$ years old, so the oldest 94 fir trees were included in the sample. 

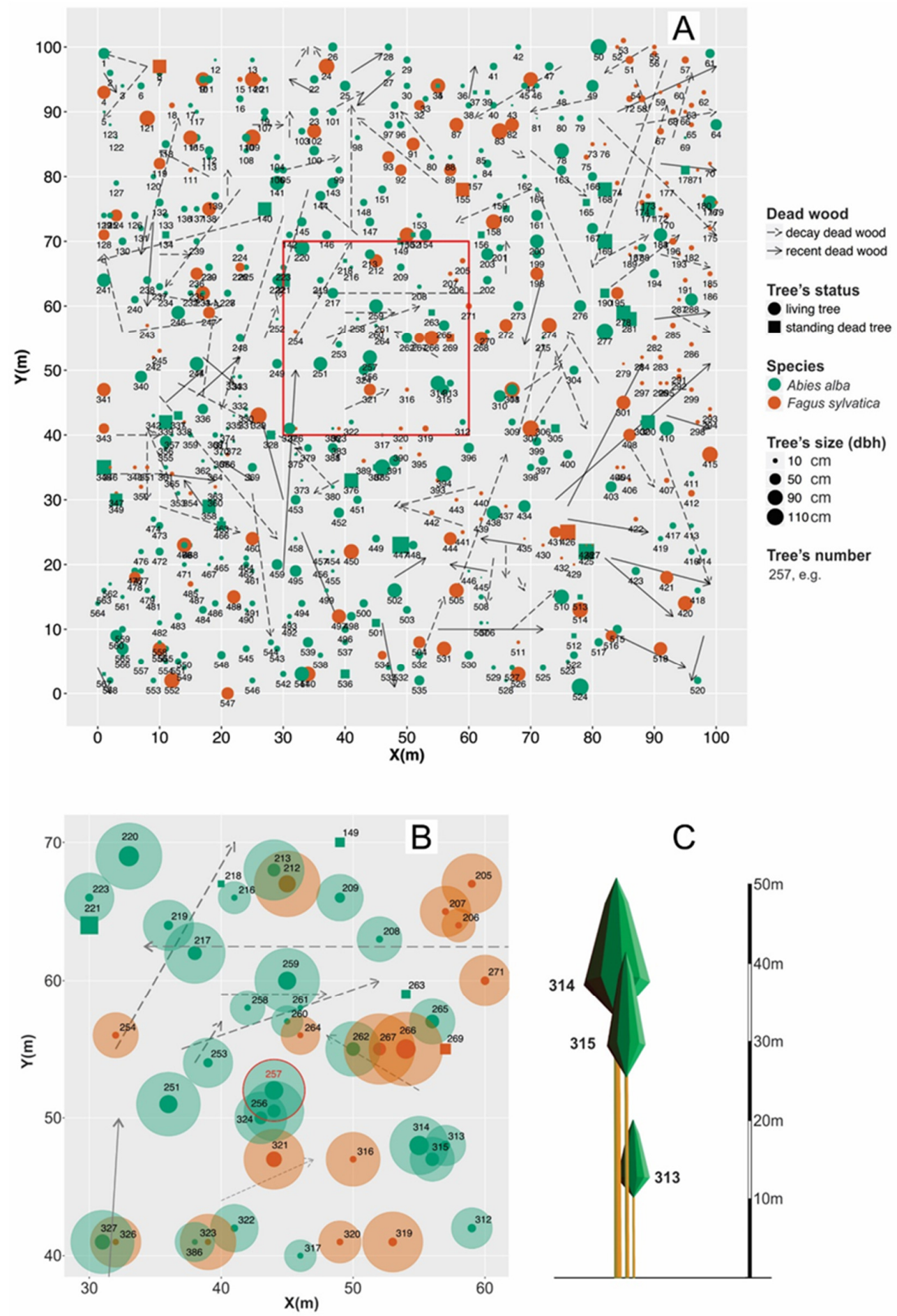

Figure 1. The spatial position of trees within the plot; (A) The position and DBH size of measured trees for the two component species, transposed in two-dimensional representation, including the dead wood on the ground (with length $\geq 3 \mathrm{~m}$ and thick-end diameter $\geq 15 \mathrm{~cm}$ ); (B) Detailed area, marked with red outline in (A), supplemented with crown's projections representation; (C) Sampled patch of neighbouring trees with different social positions 


\section{Statistical analyses}

To reveal the variation of growth trends at individual level and the relationships between growth rate, age and tree size, the tree ring series were graphically rendered (e.g. Supplementary Figure S1). The most critical phase during tree-ring data processing, from the point of view of dendroecologists (Carrer, 2011; Bowman $e t$ al., 2013), is dendrochronological standardization, an analytical technique that involves to developing a mean ring width - tree age series designed to capture the best climatic signal, but removing the biological trend by discard the variation of dendrophenotypic traits among individuals as noise (Heer et al., 2018). In this study, the interest is to analyse the whole range of individual responses to environmental change and also developmental effects among sample trees, so we use simple, non-standardized, raw ring widths retaining the original data and avoiding any data-transformation biases (Salzer et al., 2009).

An important dendroecological issue is to detect the abrupt and sustained radial growth pulses (Vašíčková et al., 2016). Therefore, the percent-growth-change (PGC) corresponding to every growth increment, except for the first and last 10 years of each series, was calculated for every tree-ring series with formula:

$\mathrm{PGC}=(\mathrm{M} 2-\mathrm{M} 1) / \mathrm{M} 1$

where $M 1$ signifies the average growth over the past 10 years (including the target year), and $M 2$ is the average growth over the subsequent 10 years (Black and Abrams, 2004). To observe the range of variation for the relationship between PGC and prior growth, all these values were plotted (Supplementary Figure S2). A release is defined as an event when the PGC exceeds a given minimum threshold (Black and Abrams, 2004). In this study, we used a threshold value of $100 \%$ to denote major growth releases (Niukkanen and Kuuluvainen, 2011 ), but we also considered the extra levels of $200 \%$ and $600 \%$ to highlight the outstanding radial growth response of trees. The PGC series, marked with all these releases, were also graphically represented (Supplementary Figure S3).

Aiming to reduce the influence of the total tree height on variability of the radial increment, the sample was split into four clusters by performing the k-means cluster analysis with Statistica10 software (StatSoft, Inc.). The four already mentioned social classes were used as initial clusters values, and the clustering variables were: tree height, cambial age, mean and variance indices (standard deviation and range of variation) of radial increment, all for the common period of record (1864-2013), and also the average radial increment for the last 50 years (1964-2013). This type of multivariate statistics uses the Euclidean distance computation and is based on the minimization of the sum of squared errors with the condition for each data element to be included to the cluster whose centroid is nearest to it. The distribution of the number of trees in clusters and the coordinates for the centroids of clusters are shown in the Supplementary Table S1.

Tree diameter increment (assumed to be twice the radial growth) is a suitable indicator for tree growth (Bowman et al., 2013; Rozas, 2015), but a better proxy aboveground woody biomass accumulation is the sectional area increment (Urrutia-Jalabert et al., 2015) that is larger, for a particular annual ring width, the larger the initial diameter of the cross-section on which it accrues (Assmann, 1970). To attenuate the possible decreasing age-related trend in radial growth attributable to increasing circumference (Schuster and Oberhuber, 2013), tree-ring width series were transformed into basal area increment (BAI) meaning the annual increase in the cross-section area of a tree trunk at $1.30 \mathrm{~m}$ height (Kunstler et al., 2016), according to the formula:

$$
\mathrm{BAI}=\pi\left(\mathrm{SR}_{\mathrm{t}}^{2}-\mathrm{SR}_{\mathrm{t}-1}^{2}\right)
$$

where $t$ is the year of a given annual ring formation and $S R$ is the corresponding stem radius (UrrutiaJalabert et al., 2015).

Separately for each recorded year of the common period, both for radial increment and for BAI, the determined values for all sampled trees $(\mathrm{N}=94)$ were distributed in classes with the amplitude of $1.0 \mathrm{~mm}$ and $10.0 \mathrm{~cm}^{2}$, respectively. For each of the two characteristics, 150 experimental distributions were obtained, graphically represented in their chronological sequence. Each stacked area chart describes how the frequencies 
of classes are divided into the four clusters. The model adopted to describe the empirical distributions was the reverse J-shaped distribution, commonly used for the analysis of horizontal structure of tree populations in uneven-aged stands (Horodnic and Roibu, 2018). This theoretical distribution is an exponential function defined by:

$$
\mathrm{N}=\mathrm{k} \cdot \mathrm{e}^{-\alpha \mathrm{x}}
$$

where $N$ represents the number of trees, $x$ is the analysed characteristic, and $k$ and $\alpha$ are specific parameters that control the shape of the curve. Both parameters increase and decrease in the same sense, being positively intercorrelated (Assmann, 1970). Their values were obtained by best-fitting each experimental distribution using ordinary least squares algorithm (Horodnic and Roibu, 2018) through a numerical optimization with Microsoft Excel solver. We used the quasi-Newton gradient-based technique, the default method available to determine the search direction in GRG (Generalized Reduced Gradient) solver, aiming to minimize the sum of squares of deviations between the observed and expected frequencies, which was chosen to be the target value for the optimization algorithm. All the distributions, for both radial increment and BAI, have been tested to assess the goodness-of-fit with the Kolmogorov-Smirnov test using the Real Statistics Resource Pack software (Zaiontz, 2015), and we concluded in every case that there is no significant difference $(p<0.01)$ between the experimental and the estimated distributions. The corresponding theoretical distribution was also graphically represented for each analysed year.

To investigate the climate-growth responses among sampled trees we used monthly gridded time series (period 1901-2013) for mean temperature, precipitation and for self-calibrated Palmer drought severity index (PDSI), obtained, for the sector in which the study area is located, from the CRU TS 3.25 data set (Harris et al., 2014; Osborn et al., 2017) available through the Climate Research Unit at the University of East Anglia. PDSI is a meteorological drought index that gives a standardized measure of soil water content at the regional scale, combining air temperature, cumulative rainfall, and field water-holding capacity (Rozas, 2015). It takes positive values for wet conditions and negative for drought, ranging approximately between -4.0 and +4.0 (Nowacki and Abrams, 1997). The climate-growth relationships were examined for every tree-ring series using the matrix of Pearson's correlation coefficients between the ring width and the selected climate variables.

Finally, a multiple regression analysis was performed with mentioned software (Zaiontz, 2015) to test, based on the adjusted coefficients of determination, which of the considered climatic factors explains better the cumulative response of the analysed trees, both for radial increment and for BAI, resulted in chronological modification of the shape of the theoretical distribution (expressed by the different values of the $\alpha$ parameter).

\section{Results and Discussion}

The inspection of chronologies for individual trees at the plot level reveals a high diversity in temporal variation of growth patterns, as is shown by the examples in the Supplementary Figure S1. The grouping of analysed trees in four clusters depending on canopy position, but also on the radial growth (Figure 2,

Supplementary Table S1) resulted in differentiation on growth response of the categories previously mentioned in other studies (Black and Abrams, 2004): permanently suppressed trees (cluster 1), co-dominant trees overtopped by adjacent trees (cluster 2), sub-dominant trees (cluster 3 ) and dominant trees (cluster 4 ) with the most sustained response.

This has diminished the variability of the height of the trees (the coefficient of variation $s \%<34.0 \%$, compared to $44.6 \%$ on the total sample) and, in a lesser degree, the dispersion of age ( $s \%<16.4 \%$ vs. $17.5 \%$ overall), but without homogenizing the growth patterns, each cluster containing almost all the previously differentiated types of radial growth (Niukkanen and Kuuluvainen, 2011): descending, even, unimodal (one peak in the growth rate) and fuzzy (no clear pattern).

Considerable variability of growth trajectories is evident within each cluster, fuzzy and even being the most common types identified, and that is a mark of the complexity of interactions found in the old-growth 
forests (Niukkanen and Kuuluvainen, 2011). The largest amplitude of variation for radial growth was observed for dominant trees, which experienced very different inter-tree interactions during their lifespans. Meanwhile, at the same scale, the suppressed trees tend to have relatively stable growth pattern at a low level.

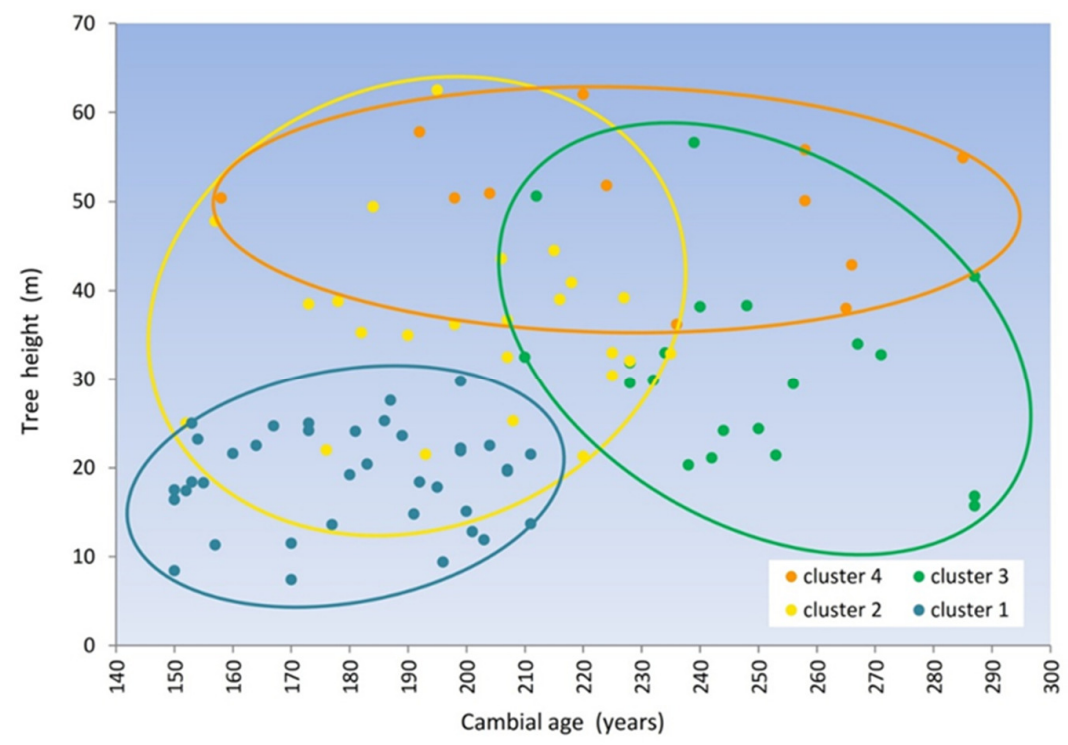

Figure 2. Cambial age - tree height graphical representation of k-cluster analysis results See Materials and Methods for details

For all ring-width series, a study of abrupt growth increments was performed with the percent-increase method (Black and Abrams, 2004), marking a release only if the PGC exceeds 100\%. From the graph corresponding to 18148 measured tree rings (Supplementary Figure S2), one can see that the maximum values of PGC decline exponentially (from the tremendous value of 1584\%) as prior growth rate increases.

The results of growth release analysis (Table 1) for last 150 years (1864-2013) indicate that $92.6 \%$ of the sampled trees record at least one release, their relative proportion within each cluster being, in descending order, as follows: $100 \%$ for cluster $4,95.0 \%$ for cluster $3,91.7 \%$ for cluster 2 , and $89.5 \%$ for cluster 1 . In 79 cases (84.0\% of the total) at least two release were observed, some (69.1\% of the total) with PGC> $200 \%$, and even with PGC> $600 \%$ ( 8 trees, 5 of them found in cluster 2 , in which they account for $20.8 \%$ of the total).

In order to check if the silver fir trees exhibited remarkably different growth patterns over the last half a century (Bosela et al., 2018), responding positively to the recent climate changes, we have analysed separately (Table 2) the growth releases that were detected for last 50 years (1964-2013).

In this period, $69.1 \%$ among the sampled trees exhibited one or more periods of abrupt growth acceleration, most of them from the cluster 2 (20 cases, reaching $83.3 \%$ of the total cluster) and, unexpectedly, from the cluster 1 ( 25 cases, meaning 65.8\%). Our data suggest that, even in lower parts of the canopy and at older ages, fir trees can greatly accelerate growth upon release, and as other studies have shown for old-growth forests with highly shade-tolerant conifers (Sillett et al., 2010; Bosela et al., 2018), these trees can often reveal multiple episodes of suppression and release. 
Table 1. Results of growth release analysis for the period of 150 years (1864-2013)

\begin{tabular}{|c|c|c|c|c|c|c|c|c|c|c|c|}
\hline \multirow{3}{*}{ Cluster* } & \multirow{3}{*}{$\begin{array}{l}\text { Number } \\
\text { of trees }\end{array}$} & \multicolumn{4}{|c|}{ PGC $>100 \%$} & \multicolumn{4}{|c|}{ PGC> $>200 \%$} & \multirow{2}{*}{\multicolumn{2}{|c|}{$\begin{array}{l}\text { PGC }>600 \% \\
1 \text { release } / \text { tree }\end{array}$}} \\
\hline & & \multicolumn{2}{|c|}{1 release/tree } & \multicolumn{2}{|c|}{$\geq 2$ releases $/$ tree } & \multicolumn{2}{|c|}{1 release/tree } & \multicolumn{2}{|c|}{$\geq 2$ releases $/$ tree } & & \\
\hline & & $\begin{array}{l}\text { Number } \\
\text { of cases }\end{array}$ & $\%$ & $\begin{array}{l}\text { Number } \\
\text { of cases }\end{array}$ & $\%$ & $\begin{array}{l}\text { Number } \\
\text { of cases }\end{array}$ & $\%$ & $\begin{array}{l}\text { Number } \\
\text { of cases }\end{array}$ & $\%$ & $\begin{array}{l}\text { Number } \\
\text { of cases }\end{array}$ & $\%$ \\
\hline 4 & 12 & 12 & 100.0 & 10 & 83.3 & 8 & 66.7 & 6 & 50.0 & 1 & 8.3 \\
\hline 2 & 24 & 22 & 91.7 & 21 & 87.5 & 20 & 83.3 & 11 & 45.8 & 5 & 20.8 \\
\hline 3 & 20 & 19 & 95.0 & 19 & 95.0 & 14 & 70.0 & 11 & 55.0 & 1 & 5.0 \\
\hline 1 & 38 & 34 & 89.5 & 29 & 76.3 & 23 & 60.5 & 10 & 26.3 & 1 & 2.6 \\
\hline Total & 94 & 87 & 92.6 & 79 & 84.0 & 65 & 69.1 & 38 & 40.4 & 8 & 8.5 \\
\hline
\end{tabular}

Table 2. Results of growth release analysis for last 50 years (1964-2013)

\begin{tabular}{|c|c|c|c|c|c|c|c|c|c|c|c|}
\hline \multirow{3}{*}{ Cluster* } & \multirow{3}{*}{$\begin{array}{l}\text { Number } \\
\text { of trees }\end{array}$} & \multicolumn{4}{|c|}{ PGC $>100 \%$} & \multicolumn{4}{|c|}{ PGC> $200 \%$} & \multirow{2}{*}{\multicolumn{2}{|c|}{$\begin{array}{l}\text { PGC }>600 \% \\
1 \text { release/tree } \\
\end{array}$}} \\
\hline & & \multicolumn{2}{|c|}{1 release/tree } & \multicolumn{2}{|c|}{$\geq 2$ releases $/$ tree } & \multicolumn{2}{|c|}{1 release/tree } & \multicolumn{2}{|c|}{$\geq 2$ releases $/$ tree } & & \\
\hline & & $\begin{array}{l}\text { Number } \\
\text { of cases }\end{array}$ & $\%$ & $\begin{array}{c}\text { Number } \\
\text { of cases }\end{array}$ & $\%$ & $\begin{array}{l}\text { Number } \\
\text { of cases }\end{array}$ & $\%$ & $\begin{array}{c}\text { Number } \\
\text { of cases }\end{array}$ & $\%$ & $\begin{array}{c}\text { Number } \\
\text { of cases }\end{array}$ & $\%$ \\
\hline 4 & 12 & 7 & 58.3 & 4 & 33.3 & 4 & 33.3 & 2 & 16.7 & 1 & 8.3 \\
\hline 2 & 24 & 20 & 83.3 & 14 & 58.3 & 15 & 62.5 & 4 & 16.7 & 4 & 16.7 \\
\hline 3 & 20 & 13 & 65.0 & 9 & 45.0 & 9 & 45.0 & 0 & 0.0 & 0 & 0.0 \\
\hline 1 & 38 & 25 & 65.8 & 14 & 36.8 & 12 & 31.6 & 1 & 2.6 & 1 & 2.6 \\
\hline Total & 94 & 65 & 69.1 & 41 & 43.6 & 40 & 42.6 & 7 & 7.4 & 6 & 6.4 \\
\hline
\end{tabular}

Visually checking all PGC series (Supplementary Figure S3), one can observe that the simultaneous releases do not occur in the same year for all trees, even limiting the analysis to a single cluster. This suggests that the factors which act simultaneously with the same intensity at the level of the entire stand (such as climatic factors) do not predominantly determine the growth pulses. Considering the proportion of trees with release, total as well as in each cluster (Figure 3), there is an increase (up to about 30\%) in releases with age of sampled trees.

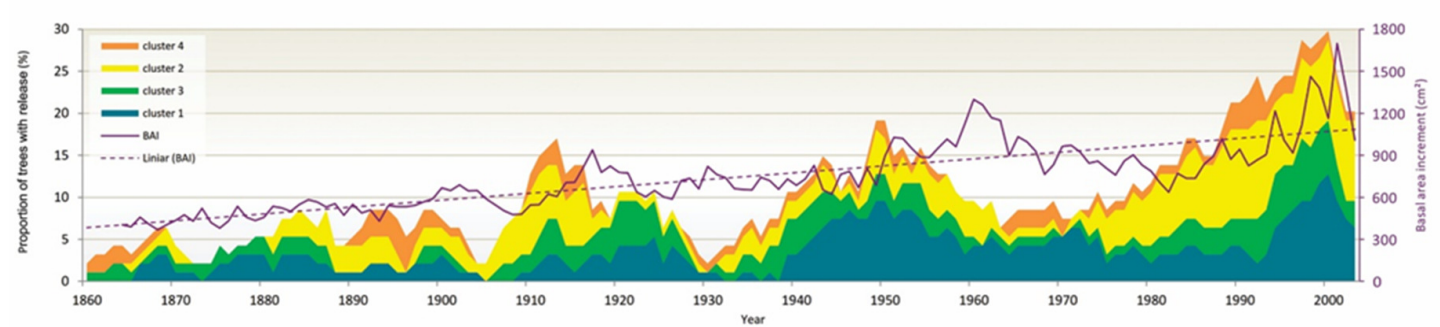

Figure 3. The trend of the proportion of releases for common growth period of trees in the studied sample The stratification is in decreasing order of the average height of the clusters. Superposed are shown the dynamics of BAI (annual values cumulated for all sampled trees, with purple solid line) and the corresponding linear trendline (purple dashed line)

The statistical analysis of the influence of climatic factors on the growth of the sampled trees took into account the monthly values of variables: mean temperature, precipitation and self-calibrated PDSI. Unlike the findings in previous studies (Schuster and Oberhuber, 2013) that highlighted distinct relationships of ring- 
width series with spring precipitation and with mid-late summer temperature, any attempt to find a common growth response, overall or within clusters, remained unsuccessful. Even after selecting consecutive months having the highest number of significant values of the correlation coefficient $(\mathrm{p}<0.05)$, and after calculating the averages for those intervals (mean March-May precipitation $-\mathrm{P}_{3-5}-$, mean July-August temperature $-\mathrm{T}_{7-8^{-}}$, and mean PDSI for vegetation season, from March to October -PDSI ${ }_{3-10}$ ), the direction and intensity of the correlations between tree-ring growth at individual level and climatic variables remained very different among the analysed trees. The distributions of the correlation coefficients, calculated for each individual chronology against the mentioned averages over the 1901-2013 period, are the most values in the range $(-0.15,+0.15)$, below the significance threshold, shifting to the positive values of the correlation coefficients only for $T_{7-8}$ (Figure 4).
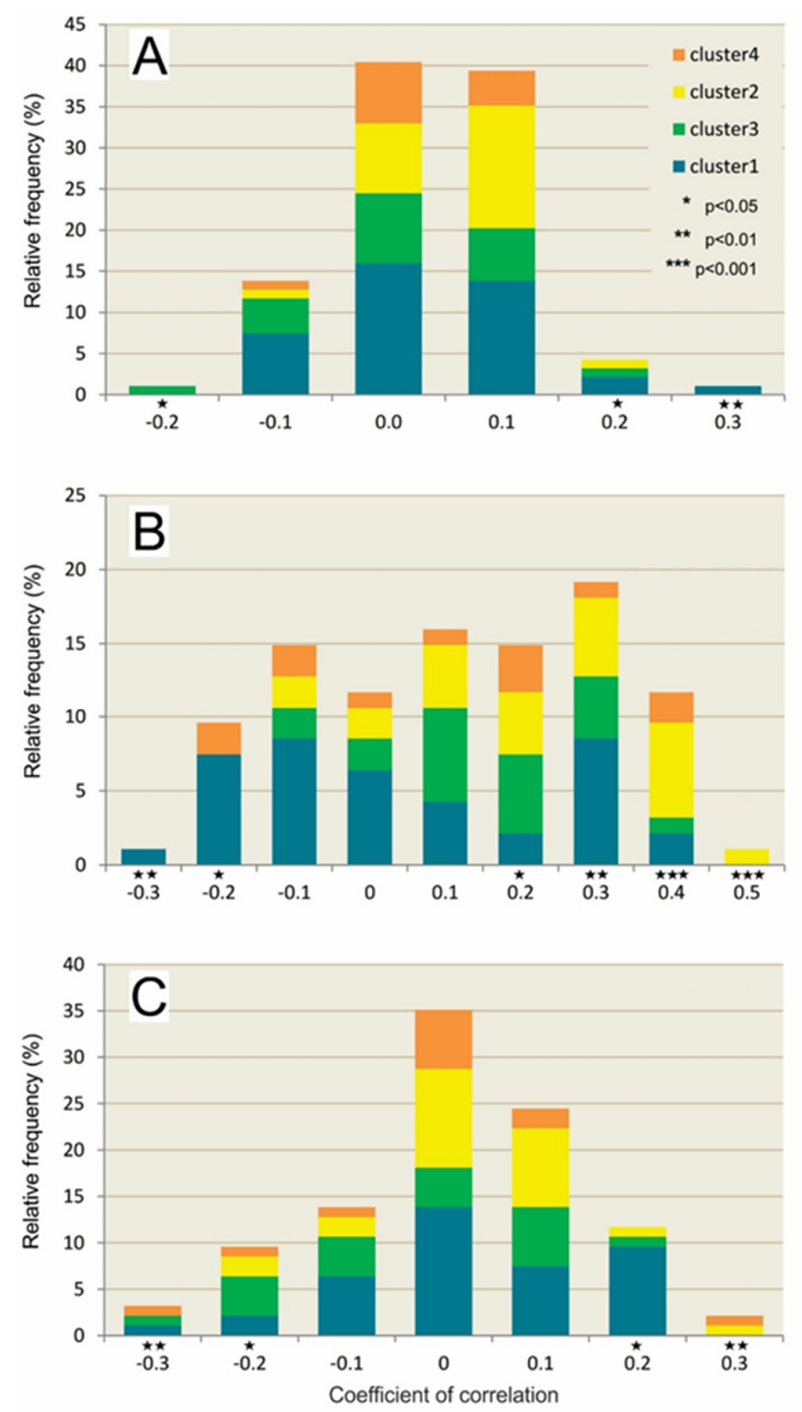

Figure 4. The distributions of the correlation coefficients calculated over the period 1901-2013 for each individual chronology against the considered climatic variables: $\mathrm{P}_{3-5}(\mathrm{~A}), \mathrm{T}_{7-8}(\mathrm{~B})$ and $\mathrm{PDSI}_{3-10}(\mathrm{C})$ The graphs show the distributions (overall, but also layered on clusters) of the relative frequencies on the correlation coefficient value categories. The associated threshold significance levels for correlation coefficients are: extremely significant $\left({ }^{* *}\right)$, very significant $\left({ }^{* *}\right)$, significant $\left({ }^{*}\right)$ and insignificant for unmarked categories 
High entropy manifested by the near-normal distribution of these correlation coefficients leads to the finding, partly revealed in other research (Michaletz et al., 2014), that in old-growth forests, even after controlling for species, tree age and social classes, the considered climatic factors explains little to none of the radial growth variation at individual tree level. More important is the positive or detrimental effect of position (Assmann, 1970), multi-aged old-growth forests being characterized by complex growth trajectories due to asynchronous canopy accession, and not synchronized like in managed ones (Di Filippo et al., 2017). In this context, it is well-known that the silver fir is particularly able to optimally use the space through vertical arrangement, at least in later stages of development (Petritan et al., 2015).

Considering all sampled trees, the analysis of the obtained experimental distributions' evolution in time, both for radial increment and for BAI, results in very expressive patterns (Figure 5).
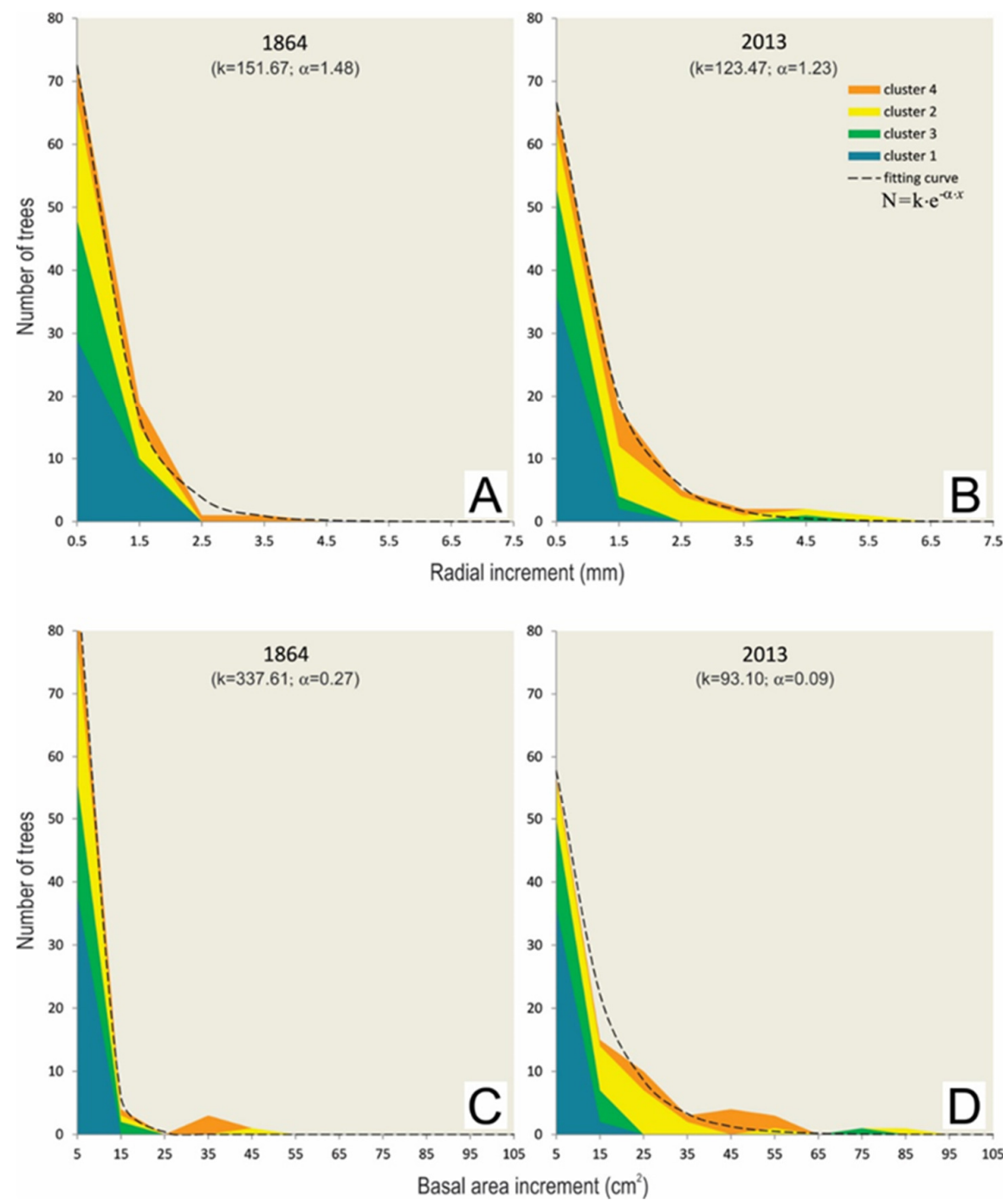

Figure 5. Collective annual growth patterns at the beginning and end of the analysed period

The stacked area charts represent the distributions of number of trees (overall, but also layered on clusters): on radial increment classes, (A) and (B); on BAI classes, (C) and (D). Black dashed lines represent the model used to best-fitting each experimental distribution, with specific parameters $k$ and $\alpha$ (see Materials and Methods for details) 
A first remark is that in the classes with the smallest increment, the number of trees decreases towards the upper limit of the analysed period. As a result, more and more trees are intensifying their growth as they become older, and this is more obvious for BAI.

Secondly, the number of trees in each class being aggregated for stacked layers corresponding to the four clusters, one can observe that in the classes with large increases there are not only dominant trees (cluster 4), that are generally growing near their optimum (Black and Abrams, 2004), but from time to time, some trees (not always the same) from clusters 2, 3 and even 1 can also be found in these classes. This denotes that fir trees of whatever social position can experience a strong growth pulse even at older ages. As a further consideration, representative trees for cluster 4 at their present cambial age that were counted for a long time in the lowgrowth classes, once advanced in the class with maximum growth do not remain permanently in this category, as we would have expected. Temporarily and at irregular intervals, those dominant trees were placed in a lower class of increase, as a consequence of several periods of depression and releases during their lifespan.

Yet, overall distribution maintains the shape provided by the negative exponential function used for fitting (see Materials and Methods). The $\alpha$ parameter of the theoretical distribution shows a general decreasing trend with time, both for radial increment and for BAI, with lower oscillations in the second case, in which it takes values between 0.34 and 0.07 , in 1875 and 2007, respectively. This decrease confirms the change in the shape of fitted distributions by a progressive horizontal extension of the curve, with trees age, to higher growth rates. The multiple stepwise regression analysis performed considering $\alpha$ as dependent variable and climatic factors $\left(\mathrm{P}_{3-5}, \mathrm{~T}_{7-8}\right.$ and $\left.\mathrm{PDSI}_{3-10}\right)$ as explanatory variables, first removed the variables with the least and undetermined contribution to the model (PDSI $\mathrm{PD}_{3-10}$ in case of radial growth, and $\mathrm{P}_{3-5}$ for $\mathrm{BAI}$ ). The two remaining independent variables with distinct significant influence $(\mathrm{p}<0.01$ for the regression coefficients) are negatively correlated with $\alpha$ (Supplementary Table S2), meaning that their increase results in a decrease of this parameter of shape, hence radial increment and BAI become larger for more trees, confirming previous studies which showed that BAI generally increased with increasing water availability and increasing temperature for spruce, fir, and beech (Rohner and al., 2018).

However, this multiple correlation explains only $26.03 \%$ of the total variation of $\alpha$ for radial increment, and only $25.43 \%$ for BAI, as denoted by adjusted R square values. This leads us to conclude that the climate factors effects in extended periods of time do not prevail in conditioning high growth rates for analysed fir trees. Narrowing the analysis to only the last 50 years, $\mathrm{T}_{7-8}$ remains the single significant independent variable, and its weight rising considerably in explaining the variation of $\alpha$ 's values ( $43.33 \%$ for radial increment and $43.48 \%$ for BAI). This confirms the well-known relationship of increased tree growth under higher temperatures (Rohner et al., 2018) and the finding that fir trees responded positively to the recent warming, exhibiting an acceleration of growth during this period (Bosela et al., 2018), but contradicts the opinion that climate influences diminish with extent of releases (Black and Abrams, 2004).

Nevertheless, the structural changes of the stand and the relationships between trees appear to influence their overall development more. The maximum growth of a particular organism is constrained by a level or range for each environmental variable (Lenton, 1998) in the context of his physical environment (sunlight; belowground obstructions) and in relation to other organisms sharing that environment (Schuster and Oberhuber, 2013; Gagliano, 2015). In order to maintain itself on low internal entropy and to compensate the entropy increase of its habitat, any organism (a tree, in this case) produces by living and growing, a process that consists in continually taking in orderliness from its environment (Schrödinger, 1945). For this, a sophisticated mechanism is needed to perceive the environment, to use and store (e.g., in the annual growth ring) the information subsequently available for behavioural adaptations (Simard, 2018).

The majority of accelerated growth represents positive reactions to canopy openings followed by a gradual decrease as neighbouring crowns occupy the gap. But in certain similar situations, with small-scale disturbances during the last 150 years and only small-gap openings, the permanently suppressed trees should have remained without any release. That is not true in many cases, which makes us infer that stand development is based on collaboration rather than on competition. In support of this idea comes the finding that 
neighbouring fir trees (e.g. Figure 1C) had simultaneous releases although they are in different social positions (dominant, co-dominant or suppressed). If competition were the only trigger, once in a dominant position a tree would continue to grow at the same rate or even at a faster rate than before, since large trees have greater capacity to acquire resources and to intercept solar radiation (Rozas, 2015). Instead, after a period of accumulation, the growth rate remained constant or was diminished and other trees, of the same species in this studied case, took the initiative in biomass accumulation, so the community maintains the same pace of development as a whole. The same finding was reached in a study in primary mountain Norway spruce forests (Trotsiuk et al., 2016).

The spatial interaction is the primary factor that influences tree growth (Assmann, 1970; Gadow and Hui, 1999), but its unequivocal explanation in terms of competition is increasingly avoided. Instead, the ecological modelling recently emphasizes the essential relevance of the functioning of each component for the benefit of the group association, leaving behind the organismic-individualistic model and fostering a more holistic approach to studying ecosystems (Simard, 2018). The highly integrated plant communities represented by forests are often characterized by supportive relations between the individual trees such as mutual adaptation or protection (Gadow and Hui, 1999), and intraspecific facilitation (Callaway and Mahall, 2007; Kunstler $e t$ al., 2011; Ehlers et al., 2016; Barker et al., 2017). These types of cooperation, widespread both within and between species, refer to any interaction that confer similar benefits to partners (Barker et al., 2017), neighbours having facilitative rather than competitive effects. In this context, it is important to highlight that kinfacilitation increases coexistence and prevails in stressful habitats with limited resources (Kunstler et al., 2011; Ehlers et al., 2016). Several hypotheses have been proposed to explain the mechanism by which plants recognize their neighbours for communicating and optimally interacting with each other, particularly between conspecifics in social groups: kin recognition through root exudates (Callaway and Mahall, 2007; Ehlers et al., 2016) or mycorrhizal fungal networks (Simard, 2018), volatile molecules emitted as warning signals, electrical signals, and neighbour-altered light-wavelength ratios (Callaway and Mahall, 2007). From this perspective, only competition is promoted in managed stands, actually eliminating the kin collaborators of a tree through the extractions made.

\section{Conclusions}

The findings presented in this study indicate that ageing did not affect the potential of silver fir trees to accumulate biomass, older trees being able to increase their growing rate. The correlations of radial increment and BAI with climatic factors differ from tree to tree in both strength and direction, even within the same cluster. Therefore, regarding trees analysed in dendrochronology it is very important to know the structure of the source forest stand, especially for periods older than 200 years, historical times with an extension of the oldgrowth forests much higher than in the current period, when the proportion changed in favour of managed forests. Also, we agree with the suggestion (Heer et al., 2018) to use every individual tree level signal in genetic association studies and not discard any as noise.

Considering the distribution by growth classes for the entire sample, the cumulative response of the analysed trees to climate change is explained especially by $T_{7-8}$, but the influence of other factors prevails, such as the small-scale disturbances or the relations with neighbouring trees, regardless of their social position. These are in line with previous research showing, on the one hand, that old trees can clearly increase their wood production (Stephenson et al., 2014) and are not carbon limited under current atmospheric CO2 concentrations (Sala et al., 2011), thus remaining important carbon sinks, and highlighting, on the other hand, the great value of old-growth forests that may be more resilient to climate change effects (Voelker, 2011).

The observed growth patterns confirm that old-growth forests are characterized by distinctive growth processes, both at the individual level, in which case it's only a matter of time until the tree will activate its 
growth, even after a long period without releases, but especially at the group level. As other studies have also shown (Carrer, 2011; Barker et al., 2017), our results confirm that the fitness components could be achieved through interactions of individuals with each other and with their environment (meaning exchange of information and associative learning), as suggested by Gagliano et al. (2016), the trees of the same species being able to obtain together a temporal plasticity in strategies, exceeding the adaptability of individuals considered separately.

\section{Authors' Contributions}

Conceptualization, S.A.H and C.C.R.; methodology, S.A.H; formal analysis, S.A.H and C.C.R.; resources, C.C.R..; writing-original draft preparation, S.A.H.; writing-review and editing, S.A.H. Both authors have read and approved the final manuscript.

\section{Acknowledgements}

We thank the University "Ştefan cel Mare" of Suceava for providing administrative and financial support. Also, we are grateful to WWF Romania for the financial and technical support for the field activities. The research leading to these results has received funding from the EEA Financial Mechanism 2009-2014 under the project contract no $18 \mathrm{SEE}$.

\section{Conflict of Interests}

The authors declare that there are no conflicts of interest related to this article.

\section{References}

Assmann E (1970). The principles of forest yield study: Studies in the organic production, structure, increment, and yield of forest stands. Pergamon Press, Oxford

Barker JL, Bronstein JL, Friesen ML, Jones EI, Reeve HK, Zink AG, Frederickson ME (2017). Synthesizing perspectives on the evolution of cooperation within and between species. Evolution 71:814-825. https://doi.org/10.1111/evo.13174

Biernaskie JM (2011). Evidence for competition and cooperation among climbing plants. Proceedings of the Royal Society B: Biological Sciences 278:1989-1996. https://doi.org/10.1098/rspb.2010.1771

Black BA, Abrams MD (2004). Development and application of boundary-line release criteria. Dendrochronologia 22:3142. https://doi.org/10.1016/j.dendro.2004.09.004

Bosela M, Lukac M, Castagneri D, Sedmák R, Biber P, Carrer M, ... Büntgen U (2018). Contrasting effects of environmental change on the radial growth of co-occurring beech and fir trees across Europe. Science of the Total Environment 615:1460-1469. https://doi.org/10.1016/j.scitotenv.2017.09.092

Bowman DMJS, Brienen RJW, Gloor E, Phillips OL, Prior LD (2013). Detecting trends in tree growth: Not so simple. Trends in Plant Science 18(1):11-17. https://doi.org/10.1016/j.tplants.2012.08.005

Callaway RM, Mahall BE (2007). Plant ecology: Family roots. Nature 448:145-147. https://doi.org/10.1038/448145a

Carrer M (2011). Individualistic and Time-Varying Tree-Ring Growth to Climate Sensitivity. PLoS One 6(7):1-8. https://doi.org/10.1371/journal.pone.0022813

Castagneri D, Storaunet KO, Rolstad J (2013). Age and growth patterns of old Norway spruce trees in Trillemarka forest, Norway. Scandinavian Journal of Forest Research 28:232-240. https://doi.org/10.1080/02827581.2012.724082 
Di Filippo A, Biondi F, Piovesan G, Ziaco E (2017). Tree ring-based metrics for assessing old-growth forest naturalness. Journal of Applied Ecology 54:737-749. https://doi.org/10.1111/1365-2664.12793

Ehlers BK, Damgaard CF, Laroche F (2016). Intraspecific genetic variation and species coexistence in plant communities. Biology Letters 12:20150853. https://doi.org/10.1098/rsbl.2015.0853

Gadow KV, Hui G (1999). Modelling Forest Development. Forestry Sciences Series, Kluwer Academic Publishers, Dordrecht. https://doi.org/10.1007/978-94-011-4816-0

Gagliano M (2015). In a green frame of mind: perspectives on the behavioural ecology and cognitive nature of plants. AoB Plants 7:plu075. https://doi.org/10.1093/aobpla/plu075

Gagliano M, Vyazovskiy VV, Borbély AA, Grimonprez M, Depczynski M (2016). Learning by association in plants. Scientific Reports 6: 38427. https://doi.org/10.1038/srep38427

Harris I, Jones PD, Osborn TJ, Lister DH (2014). Updated high-resolution grids of monthly climatic observations - the CRU TS3.10 Dataset. International Journal of Climatology 34:623-642. https://doi.org/10.1002/joc.3711

Heer K, Behringer D, Piermattei A, Bässler C, Brandl R, Fady B, ... Opgenoorth L (2018). Linking dendroecology and association genetics in natural populations: stress responses archived in tree rings associate with SNP genotypes in silver fir (Abies alba Mill.). Molecular Ecology 27(6):1428-1438. https://doi.org/10.1111/mec.14538

Horodnic SA, Roibu CC (2018). A Gaussian multi-component model for the tree diameter distribution in old-growth forests. European Journal of Forest Research 137:185-196. https://doi.org/10.1007/s10342-017-1097-5

Kunstler G, Albert CH, Courbaud B, Lavergne S, Thuiller W, Vieilledent G, ... Coomes DA (2011). Effects of competition on tree radial-growth vary in importance but not in intensity along climatic gradients. Journal of Ecology 99(1):300-312. https://doi.org/10.1111/j.1365-2745.2010.01751.x

Kunstler G, Falster D, Coomes DA, Hui F, Kooyman RM, Laughlin DC, ... Westoby M (2016). Plant functional traits have globally consistent effects on competition. Nature 529(7571):204-207. https://doi.org/10.1038/nature16476

Lenton TM (1998). Gaia and natural selection. Nature 394:439-447. https://doi.org/10.1038/28792

Michaletz ST, Cheng D, Kerkhoff AJ, Enquist BJ (2014). Convergence of terrestrial plant production across global climate gradients. Nature 512:39-43. https://doi.org/10.1038/nature13470

Niukkanen L, Kuuluvainen T (2011). Radial growth patterns of dominant trees in two old-growth forests in eastern Fennoscandia. Journal of Forest Research 16(3):228-236. https://doi.org/10.1007/s10310-011-0259-4

Nowacki GJ, Abrams MD (1997). Radial-growth averaging criteria for reconstructing disturbance histories from presettlement-origin oaks. Ecological Monographs 67(2):225-249. https://doi.org/10.2307/2963514

Osborn TJ, Barichivich J, Harris I, van der Schrier G, Jones PD (2017). Monitoring global drought using the selfcalibrating Palmer Drought Severity Index. State of the Climate in 2016. Bulletin of the American Meteorological Society 98:S32-S33

Petritan IC, Commarmot B, Hobi ML, Petritan AM, Bigler C, Abrudan IV, Rigling A (2015). Structural patterns of beech and silver fir suggest stability and resilience of the virgin forest Sinca in the Southern Carpathians, Romania. Forest Ecology and Management 356:184-195. https://doi.org/10.1016/j.foreco.2015.07.015

Pretzsch H (2009). Forest Dynamics, Growth, and Yield. In: Forest Dynamics, Growth and Yield: from measurement to model. Springer, Berlin, Heidelberg pp. 1-39. https://doi.org/10.1007/978-3-540-88307-4_1

Rohner B, Waldner P, Lischke H, Ferretti M, Thürig E (2018). Predicting individual-tree growth of central European tree species as a function of site, stand, management, nutrient, and climate effects. European Journal of Forest Research 137:29-44. https://doi.org/10.1007/s10342-017-1087-7

Rozas V (2015). Individual-based approach as a useful tool to disentangle the relative importance of tree age, size and inter-tree competition in dendroclimatic studies. iForest 8:187-194. https://doi.org/10.3832/ifor1249-007

Ryan MG, Binkley D, Fownes JH (1997). Age-related decline in forest productivity: pattern and process. Advances in Ecological Research 27:213-262. https://doi.org/10.1016/S0065-2504(08)60009-4

Sala A, Fouts W, Hoch G (2011). Carbon storage in trees: Does relative carbon supply decrease with tree size? In: Meinzer FC, Lachenbruch B, Dawson TE (Eds). Size- and Age-Related Changes in Tree Structure and Function. Springer, Berlin, Germany pp. 287-306. https://doi.org/10.1007/978-94-007-1242-3

Salzer MW, Hughes MK, Bunn AG, Kipfmueller KF (2009). Recent unprecedented tree-ring growth in bristlecone pine at the highest elevations and possible causes. Proceedings of the National Academy of Sciences of the United States of America 106(48):20348-20353. https://doi.org/10.1073/pnas.0903029106 
Schrödinger E (1945). What is Life? Cambridge University Press, New York.

Schuster R, Oberhuber W (2013). Age-dependent climate-growth relationships and regeneration of Picea abies in a drought-prone mixed coniferous forest in the Alps. Canadian Journal of Forest Research 43(7):609-618. https://doi.org/10.1139/cjfr-2012-0426

Simard SW (2018). Mycorrhizal Networks Facilitate Tree Communication, Learning, and Memory. In: Baluska F, Gagliano M, Witzany G (Eds.) Memory and Learning in Plants. Signaling and Communication in Plants (pp. 191-213). Springer, Cham. https://doi.org/10.1007/978-3-319-75596-0_10

Sillett SC, Van Pelt R, Koch GW, Ambrose AR, Carroll AL, Antoine ME, Mifsud BM (2010). Increasing wood production through old age in tall trees. Forest Ecology and Management 259(5):976-994. https://doi.org/10.1016/j.foreco.2009.12.003

Stephenson NL, Das AJ, Condit R, Russo SE, Baker PJ, Beckman NG, ... Zavala MA (2014). Rate of tree carbon accumulation increases continuously with tree size. Nature 507:90-93. https://doi.org/10.1038/nature12914

Trotsiuk V, Svoboda M, Weber P, Pederson N, Klesse S, Janda P, ... Frank D (2016). The legacy of disturbance on individual tree and stand-level aboveground biomass accumulation and stocks in primary mountain Picea abies forests. Forest Ecology and Management 373:108-115. https://doi.org/10.1016/j.foreco.2016.04.038

Urrutia-Jalabert R, Malhi Y, Barichivich J, Lara A, Delgado-Huertas A, Rodríguez CG, Cuq E (2015). Increased water use efficiency but contrasting tree growth patterns in Fitzroya cupressoides forests of southern Chile during recent decades. Journal of Geophysical Research-Biogeosciences 120:2505-2524. https://doi.org/10.1002/2015JG003098

Vašičková I, Šamonil P, Fuentes UAE, Král K, Daněk P, Adam D (2016). The true response of Fagus sylvatica L. to disturbances: A basis for the empirical inference of release criteria for temperate forests. Forest Ecology and Management 374:174-185. https://doi.org/10.1016/j.foreco.2016.04.055

Voelker SL (2011). Age-dependent changes in environmental influences on tree growth and their implications for forest responses to climate change. In: Meinzer FC, Lachenbruch B, Dawson TE (Eds). Size- and age-related changes in tree structure and function. Springer, Berlin, Germany pp. 455-479. https://doi.org/10.1007/978-94-007$1242-3 \quad 17$

Zaiontz C (2015). Real statistics using Excel. Retrieved 2020 June 14 from http://www.real-statistics.com
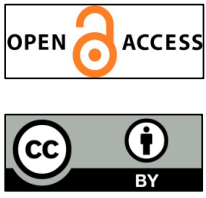

The journal offers free, immediate, and unrestricted access to peer-reviewed research and scholarly work. Users are allowed to read, download, copy, distribute, print, search, or link to the full texts of the articles, or use them for any other lawful purpose, without asking prior permission from the publisher or the author.

License - Articles published in Notulae Botanicae Horti Agrobotanici Cluj-Napoca are Open-Access, distributed under the terms and conditions of the Creative Commons Attribution (CC BY 4.0) License.

(c) Articles by the authors; UASVM, Cluj-Napoca, Romania. The journal allows the author(s) to hold the copyright/to retain publishing rights without restriction. 


\section{Supplementary files}
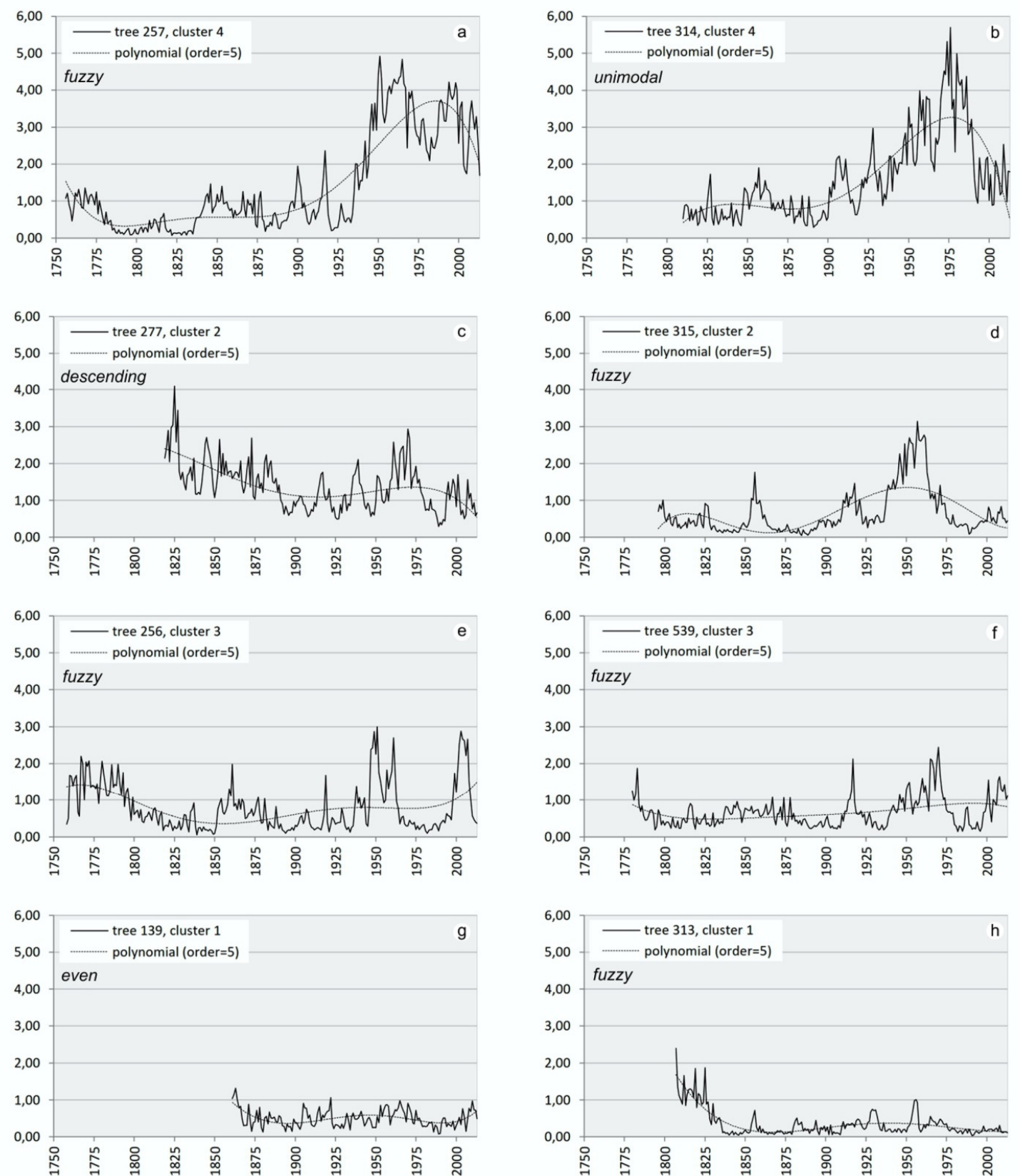

Figure S1. Examples of tree-ring growth patterns. For each cluster, two of the tree ring series were graphically rendered: for the trees with numbers 257 (a) and 314 (b) in cluster 4, for the trees with numbers 277 (c) and 315 (d) in cluster 2, for the trees with numbers $256(\mathbf{e})$ and $539(\mathbf{f})$ in cluster 3, and for the trees with numbers $139(\mathbf{g})$ and $313(\mathbf{h})$ in cluster 1 . Using a fifth-order polynomial trendline (dashed line) were differentiated the four types of radial growth: fuzzy (a, d, e, f and $\mathbf{h}$ ), unimodal (b), descending $(\mathbf{c})$ and even (g). 
Horodnic SA and Roibu CC (2020). Not Bot Horti Agrobo 48(2):1085-1099

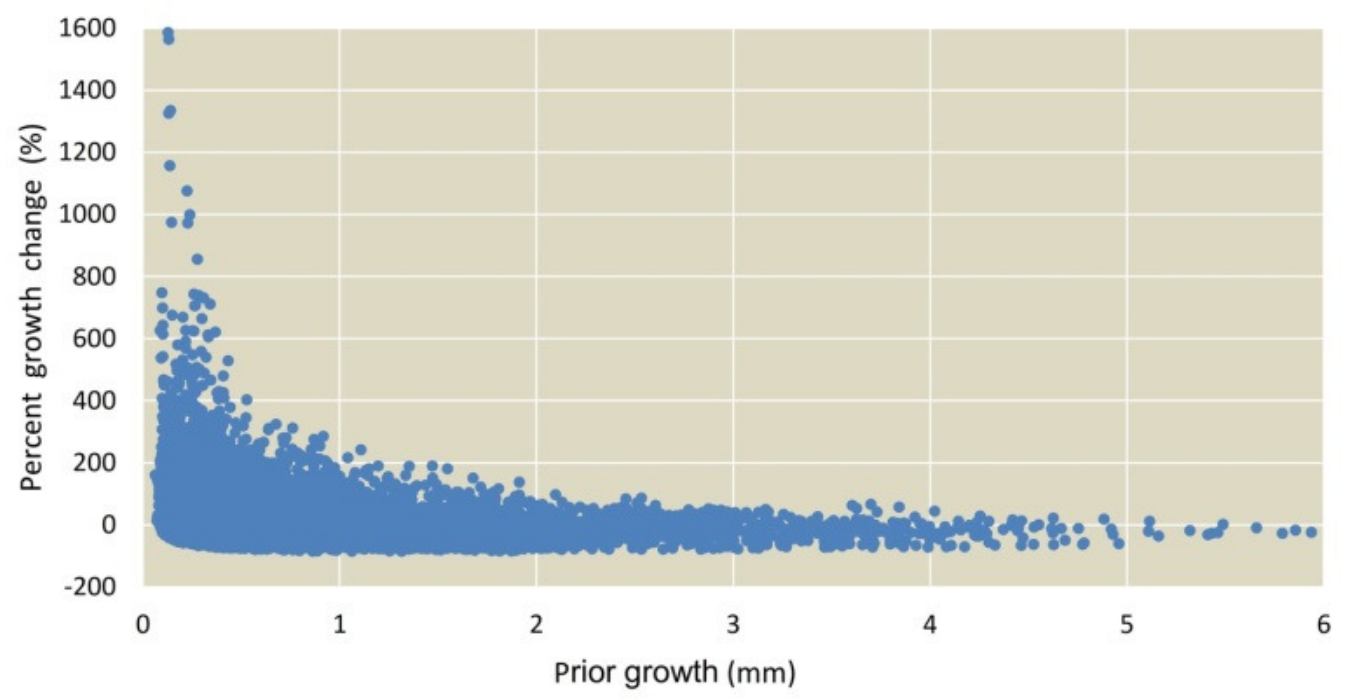

FigureS2. Plot of PGC against priorgrowth for 18148 measured tree ring widths. See Materials and Methods for details. 


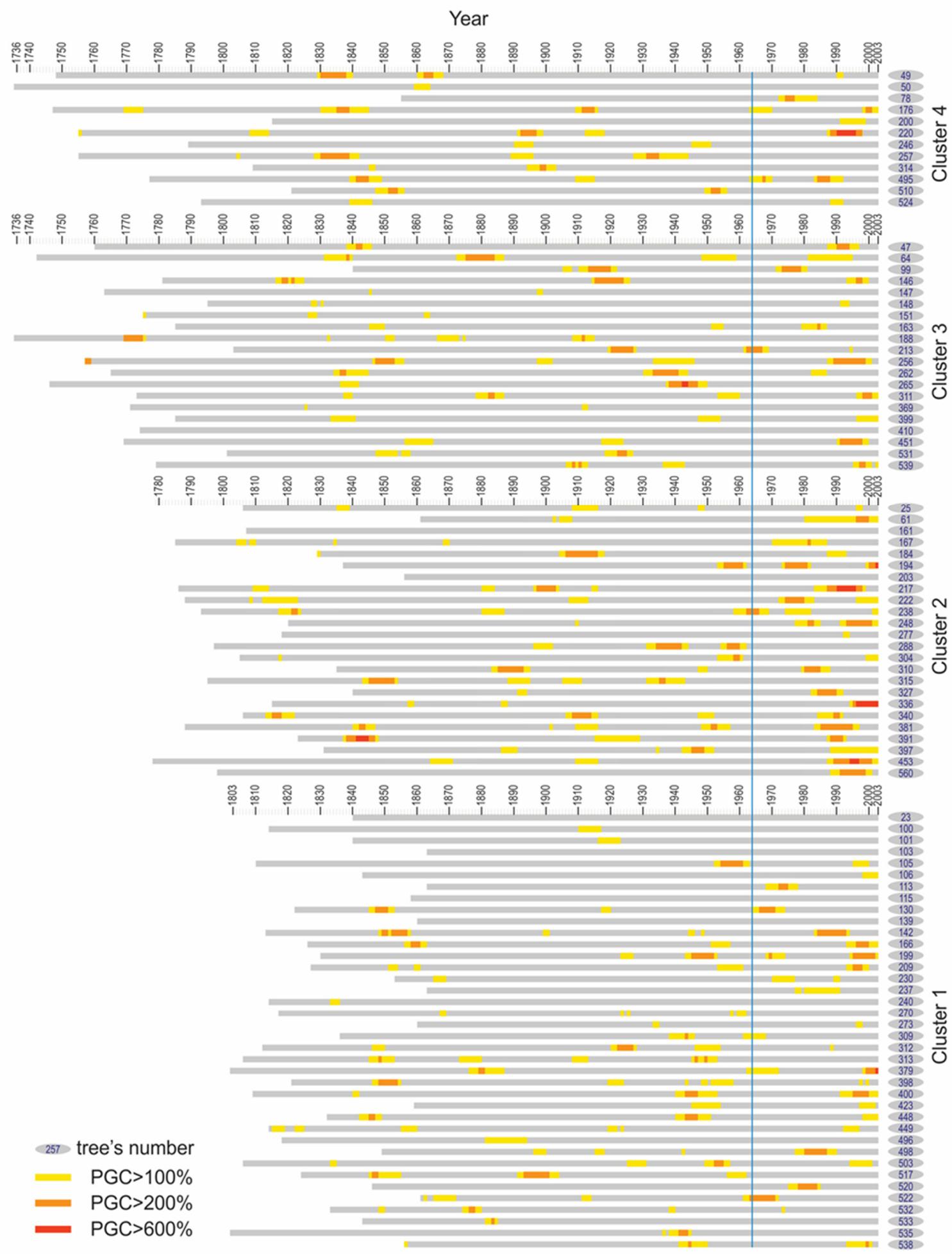

Figure S3. PGC series for the oldest 94 fir trees included in the sample. The clusters were arranged in increasing order of size and all periods with releases are marked with the colors code matching the legend. The blue line delimits the growth releases that were detected for last 50 years (19642013) 
TableS1. The grouping of analyzed trees as result of k-means cluster analysis

\begin{tabular}{|c|c|c|c|c|c|c|c|c|c|c|}
\hline \multirow{4}{*}{ Cluster } & \multicolumn{6}{|c|}{ Coordinates for the centroids of clusters } & \multirow{4}{*}{$\begin{array}{c}\text { Number } \\
\text { of cases }\end{array}$} & \multirow{3}{*}{ Percentage } & \multirow{2}{*}{\multicolumn{2}{|c|}{$s \%$ for }} \\
\hline & \multirow[b]{2}{*}{$\mathbf{h}$} & \multicolumn{4}{|c|}{ Indices of radial increment } & \multirow[b]{2}{*}{ vcamb } & & & & \\
\hline & & $\mathbf{s}$ & $\mathbf{w}$ & $\begin{array}{c}\text { ir } \\
\text { med }\end{array}$ & $\begin{array}{l}\text { ir } 50 \\
\text { med }\end{array}$ & & & & h & vcamb \\
\hline & $(\mathbf{m})$ & $(\mathbf{m m})$ & $(\mathrm{mm})$ & $(\mathrm{mm})$ & $(\mathbf{m m})$ & (years) & & $(\%)$ & $(\%)$ & $(\%)$ \\
\hline 1 & 18.89 & 0.29 & 1.55 & 0.44 & 0.42 & 180.24 & 38 & 40.4 & 29.3 & 11.3 \\
\hline 2 & 35.98 & 0.71 & 3.74 & 0.87 & 1.11 & 200.63 & 24 & 25.5 & 26.8 & 11.4 \\
\hline 3 & 31.12 & 0.40 & 2.15 & 0.56 & 0.50 & 247.65 & 20 & 21.3 & 33.9 & 9.2 \\
\hline 4 & 50.10 & 1.13 & 5.10 & 1.75 & 1.90 & 230.33 & 12 & 12.8 & 15.4 & 16.4 \\
\hline & & & & & & & & Overall & 44.6 & 17.5 \\
\hline
\end{tabular}

The clusteringvariables were: tree height $(\mathrm{h})$, cambial age (vcamb), standard deviation of radial increment $(\mathrm{s})$, range of variation of radial increment (w), mean of radial increment (ir med), all for the common period (18642013), and also the average radial increment for the last 50 years (ir 50 med). $s \%=\frac{s}{\bar{x}} \cdot 100$ is the coefficient of variation.

Table S2. Results of multiple stepwise regression analysis with $\alpha$ as dependent variable and the climatic factors $\left(\mathrm{P}_{355}, \mathrm{~T}_{7-8}\right.$ and PDSI3-10) as explanatoryvariables

\begin{tabular}{|c|c|c|c|c|c|c|c|c|}
\hline & \multicolumn{2}{|c|}{ Coefficient } & t stat & p-value & lower & upper & & \\
\hline Regression function & \multicolumn{4}{|c|}{$\propto_{R I}=a_{0}+a_{1} \cdot P_{3-5}+a_{2} \cdot T_{7-8}$} & \multicolumn{2}{|c|}{ (period: 1901-2013) } & Multiple $\mathrm{R}=$ & 0.5230 \\
\hline Intercept & $a_{0}$ & 4.42891 & 9.38566 & $1 \mathrm{E}-15$ & 3.49375 & 5.36407 & $\mathrm{R}^{2}=$ & 0.2735 \\
\hline$P_{3-5}$ & $a_{1}$ & -0.00449 & -3.20005 & 0.001796 & -0.00727 & -0.00171 & Adjusted $\mathrm{R}^{2}=$ & 0.2603 \\
\hline $\mathrm{T}_{7-8}$ & $a_{2}$ & -0.15938 & -5.64722 & $1.29 \mathrm{E}-07$ & -0.21531 & -0.10345 & Observations $=$ & 113 \\
\hline Regression function & \multicolumn{4}{|c|}{$\propto_{B A I}=a_{0}+a_{1} \cdot T_{7-8}+a_{2} \cdot P D S I_{3-10}$} & \multicolumn{2}{|c|}{ (period: 1901-2013) } & Multiple $\mathrm{R}=$ & 0.5173 \\
\hline Intercept & $a_{0}$ & 0.50943 & 9.20881 & $2.54 \mathrm{E}-15$ & 0.36442 & 0.65443 & $\mathrm{R}^{2}=$ & 0.2676 \\
\hline $\mathrm{T}_{7-8}$ & $a_{1}$ & -0.02183 & -6.30728 & 6.09E-09 & -0.03090 & -0.01276 & Adjusted $\mathrm{R}^{2}=$ & 0.2543 \\
\hline $\mathrm{PDSI}_{3-10}$ & $a_{2}$ & -0.00524 & -2.84556 & 0.005289 & -0.01007 & -0.00041 & Observations $=$ & 113 \\
\hline Regression function & \multicolumn{4}{|c|}{$\propto_{R I}=b_{0}+b_{1} \cdot T_{7-8}$} & \multicolumn{2}{|c|}{ (period: 1964-2013) } & $\mathrm{R}=$ & 0.6670 \\
\hline Intercept & $b_{0}$ & 5.08573 & 8.81038 & $1.35 \mathrm{E}-11$ & 3.53745 & 6.63401 & Adjusted $\mathrm{R}^{2}=$ & 0.4333 \\
\hline $\mathrm{T}_{7-8}$ & $b_{1}$ & -0.22292 & -6.20248 & $1.23 \mathrm{E}-07$ & -0.31932 & -0.12652 & Observations $=$ & 50 \\
\hline Regression function & \multicolumn{4}{|c|}{$\propto_{B A I}=b_{0}+b_{1} \cdot T_{7-8}$} & \multicolumn{2}{|c|}{ (period: 1964-2013) } & $\mathrm{R}=$ & 0.6681 \\
\hline Intercept & $b_{0}$ & 0.50252 & 8.63411 & $2.47 \mathrm{E}-11$ & 0.34641 & 0.65863 & Adjusted $\mathrm{R}^{2}=$ & 0.4348 \\
\hline $\mathrm{T}_{7-8}$ & $b_{1}$ & -0.02254 & -6.22116 & $1.15 \mathrm{E}-07$ & -0.03226 & -0.01282 & Observations $=$ & 50 \\
\hline
\end{tabular}

tstatrepresentst-testvalueand is used to test the significance of each predictor in the equation: the larger thisvalueis, the moreimportant thevariable. Thestatistical significance is the two-tail p-value: the smaller thisp-value, the more important the independentvariable is. The limitslower and upper represent the $95 \%$ confidenceinterval for calculated coefficients.Multiple $R$ and $R$ arethe coefficients of correlation multipleand simple, respectively. $R^{2}$ and $A d j u s t e d R^{2}$ are the coefficients of determination, the latter taking into account also the degrees of freedom and number of explanatory variables. 